\title{
REVIEW
}

\section{Cardiac output monitoring: an integrative perspective}

\author{
Jamal A Alhashemi', Maurizio Cecconi², Christoph K Hofer ${ }^{3 *}$ \\ This article is one of eleven reviews selected from the Annual Update in Intensive Care and Emergency Medicine 2011 (Springer Verlag) and \\ co-published as a series in Critical Care. Other articles in the series can be found online at http://ccforum.com/series/annual. Further \\ information about the Annual Update in Intensive Care and Emergency Medicine is available from http://www.springer.com/series/8901
}

\begin{abstract}
Introduction
Cardiac output monitoring in the critically ill patient is standard practice in order to ensure tissue oxygenation [1] and has been traditionally accomplished using the pulmonary artery catheter (PAC). In recent years, however, the value of PAC has been questioned with some suggesting that its use might not only be unnecessary but also potentially harmful [1]. This notion, together with the availability of new less invasive cardiac output measuring devices, has markedly decreased the widespread use of the PAC [2]. Today, various devices are available to measure or estimate cardiac output using different methods. Some of these less invasive devices track stroke volume (SV) continuously and provide dynamic indices of fluid responsiveness, others allow assessment of volumetric preload variables, and some also provide continuous measurement of central venous saturation via the use of proprietary catheters that are attached to the same monitor. All these variables together with cardiac output - may result in an improved hemodynamic assessment of the critically ill patient. However, it is important to appreciate that each device has its inherent limitations and that no cardiac output monitoring device can change patient outcome unless its use is coupled with an intervention that by itself has been associated with improved patient outcomes. Therefore, the concept of hemodynamic optimization is increasingly recognized as a cornerstone in the management of critically ill patients and has been shown to be associated with improved outcome in the perioperative [3] and in the intensive care unit (ICU) [4] setting.
\end{abstract}

*Correspondence: christoph.hofer@triemli.stzh.ch

Institute of Anesthesiology and Intensive Care Medicine, Triemli City Hospital, Birmensdorfersr. 497, 8063 Zurich, Switzerland

Full list of author information is available at the end of the article
The aim of this article is to provide a systematic update of the currently available and most commonly used cardiac output monitoring devices. In addition, an integrated approach for the use of these different devices in critically ill patients will be presented taking into consideration the devices' technical characteristics, their performance and typical limitations, and also any additional hemodynamic variables they may offer.

\section{Overview of cardiac output monitoring devices}

When selecting a cardiac output monitoring device for clinical use, different factors play a role (Table 1): Institutional factors may largely limit the choice of the available devices. On the other hand important device-related factors, e.g., invasiveness (Fig. 1), may restrict the area of application. Moreover, patient specific conditions may dictate the use of an invasive or a particular minimallyor non-invasive device.

\section{Invasive cardiac output monitoring}

The PAC was the clinical standard for cardiac output monitoring for more than 20 years and the technique has been extensively investigated. Its complications are well known and despite developments in recent years, the PAC has a distinct role in patient care. An in-depth review is beyond the scope of this article, but some technical aspects and limitations need to be noted: Cardiac output measurement by intermittent pulmonary artery thermodilution, which is based on the StewartHamilton principle, is considered to be the 'reference cardiac output monitoring standard' against which all new cardiac output measuring devices are compared. However, operator dependence, various patient conditions (e.g., mitral or tricuspid valve insufficiency, shunt) or misplacement of the PAC may influence reliable cardiac output assessment [6]. In contrast, continuous cardiac output assessment may overcome some of these

\section{CiöMed Central}

(c) 2011 Springer-Verlag Berlin Heidelberg.

This work is subject to copyright. All rights are reserved, whether the whole or part of the material is concerned, specifically the rights of translation, reprinting, reuse of illustrations, recitation, broadcasting, reproduction on microfilm or in any other way, and storage in data banks. Duplication of this publication or parts thereof is permitted only under the provisions of the German Copyright Law of September 9 , 1965 , in its current version, and permission for use must always be obtained from Springer-Verlag. Violations are liable for prosecution under the German Copyright Law. 
Table 1. Factors affecting selection of cardiac output monitoring devices

\begin{tabular}{ll}
\hline Factor groups & Examples \\
\hline Institution & Type of institution \\
& Availability of monitoring techniques \\
& Level of standardization \\
& Potential of integration into existing monitoring systems \\
& Level of experience \\
Invasiveness & Handling \\
& Technical limitations \\
& Validity, accuracy \& repeatability \\
& Availability of additional hemodynamic information \\
& Severity of specific diseases \\
& Heart rhythm \\
Patient & Contraindications \\
& Type of intervention \\
& Type of treatment protocol
\end{tabular}

limitations. Intermittent thermal filament heating induces pulmonary artery temperature changes that are measured via a distal thermistor and matched with the input signal. Based on the cross correlation of in- and output signals intermittent cardiac output values are produced from a thermodilution wash-out curve. These values are then averaged for the display of continuous cardiac output readings, which results in a delayed response time of several minutes after induction of cardiac output changes (e.g., for Opti- $\mathrm{Q}^{\mathrm{TM}}$, Abbott, Abbott Park, IL and Vigilance ${ }^{\mathrm{TM}}$ catheters, Edwards LifeSiences, Irvine, CA) [7]. A so-called fast response continuous cardiac output catheter (truCCOMS ${ }^{\mathrm{TM}}$, Omega Critical Care, East Klibride, GB) allows a more synchronized continuous cardiac output monitoring [8]. The additional hemodynamic variables that can be assessed via PAC and are most often used are conventional filling pressures, pulmonary artery pressures, and mixed venous oxygen saturation $\left(\mathrm{SvO}_{2}\right)$. Therefore, the PAC is still indicated when additional monitoring of pulmonary artery pressures and $\mathrm{SvO}_{2}$ is desirable. It is also indicated in situations where less invasive techniques are contraindicated or fail to provide accurate cardiac output values.

\section{Minimally invasive cardiac output monitoring}

Minimally invasive cardiac output monitoring devices use one of four main principles to measure cardiac output: Pulse contour analysis, pulsed Doppler technology, applied Fick principle, and bioimpedance/bioreactance. Furthermore, devices that use pulse contour analysis can also be classified into calibrated and uncalibrated systems.

\section{Pulse pressure analysis}

Pulse pressure analysis is based on the principle that SV can be continuously estimated by analyzing the arterial pressure waveform obtained from an arterial line. The characteristics of the arterial pressure waveform are affected by the interaction between SV and individual vascular compliance, aortic impedance and peripheral arterial resistance. For reliable cardiac output measurement using all devices that employ pulse pressure analysis technology, optimal arterial waveform signal (i.e., eliminating damping or increased tubing resonance) is a prerequisite. Moreover, it cannot be overemphasized that severe arrhythmias may reduce the accuracy of cardiac output measurement, and that the use of an intra-aortic balloon pump precludes adequate performance of the device. Furthermore, pulse pressure analysis may be of

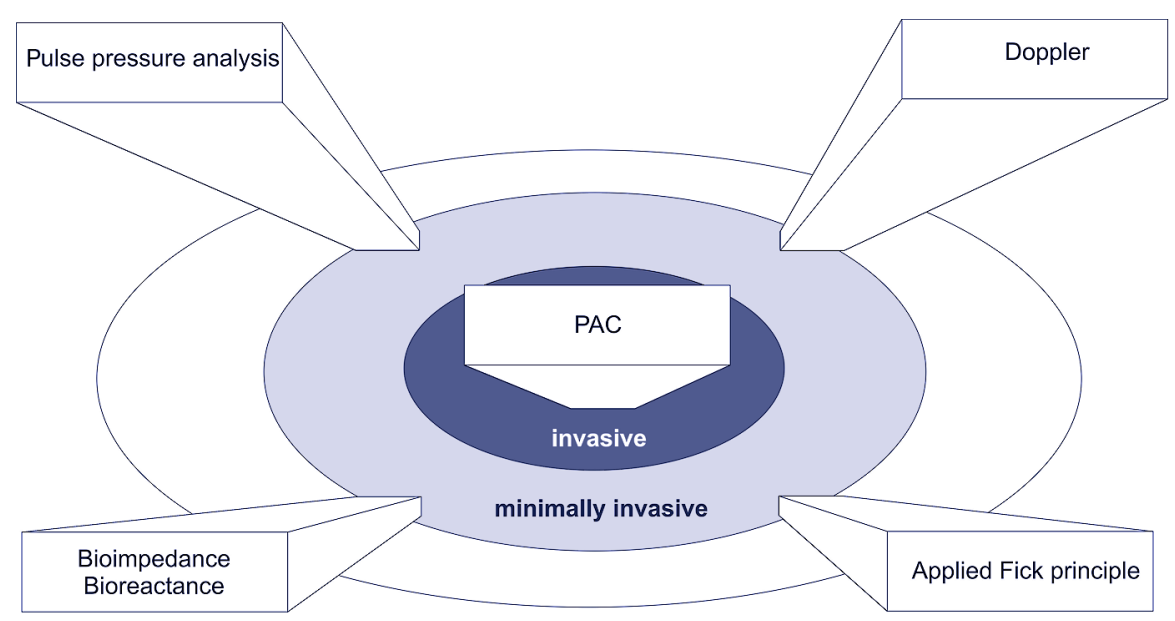

Figure 1. Overview of cardiac output monitoring techniques. PAC: pulmonary artery catheter. 
limited accuracy during periods of hemodynamic instability, i.e., rapid changes in vascular resistance. This may especially be a problem for uncalibrated pulse pressure analysis. In contrast, calibrated pulse pressure analysis may require frequent re-calibration for accurate cardiac output estimation in these situations. A growing number of calibrated and uncalibrated devices that measure the cardiac output based on the pulse pressure analysis method are available.

PiCCOplus ${ }^{\mathrm{TM}}$ system (Pulsion Medical Systems, Munich, Germany): The $\mathrm{PiCCO}^{\mathrm{TM}}$ system uses a dedicated thermistor-tipped catheter, which is typically placed in the femoral artery, in order to assess SV on a beat-to-beat basis. Alternatively a radial or brachial catheter may be employed, but these catheters have to be longer than the femoral one for the adequate assessment of the aortic arterial pressure wave signal. Cardiac output calibration via transpulmonary thermodilution requires the insertion of a central venous line. The calibration process is also used for the adjustment of individual aortic impedance and needs to be repeated every eight hours in hemodynamically stable patients. However, during situations of hemodynamic instability, calibration needs to be done more frequently (eventually every hour) [9]. Nevertheless, a variety of studies have successfully validated the PiCCOplus ${ }^{\mathrm{TM}}$ system in different patient populations $[10,11]$.

The launch of an uncalibrated device from Pulsion Medical Systems, the PulsioFlex ${ }^{\mathrm{TM}}$ system, can be expected in 2011. The system will require a specific additional sensor, which can be connected to a regular invasive arterial pressure monitoring set.

$\mathrm{LiDCO}^{\mathrm{TM}}$ plus and $\mathrm{LiDCO}^{\mathrm{TM}}$ rapid system: The $\mathrm{LiDCO}^{\mathrm{TM}}$ plus and $\mathrm{LiDCO}^{\mathrm{TM}}$ rapid systems (LiDCO Ltd, London, UK) use the same pulse pressure algorithm $\left(\right.$ PulseCO ${ }^{\mathrm{TM}}$ ) to track continuous changes in SV. This algorithm is based on the assumption that the net power change in the system in a heartbeat is the difference between the amount of blood entering the system (SV) and the amount of blood flowing out peripherally. It uses the principle of conservation of mass (power) and assumes that following correction for compliance there is a linear relationship between netpower and netflow. Therefore, the LiDCO systems should be considered as pulse power analysis techniques. The $\mathrm{LiDCO}^{\mathrm{TM}}$ plus requires calibration using the transpulmonary lithium indicator dilution technique, which can be performed via a peripheral venous line [12]. In contrast, the $\mathrm{LiDCO}^{\mathrm{TM}}$ rapid uses nomograms for cardiac output estimation. Clinical studies have demonstrated reliable estimation of cardiac output using PulseCO as long as no major hemodynamic changes are observed [13]. Regarding the $\mathrm{LiDCO}^{\mathrm{TM}}$ plus, the reliability of the lithium calibration system may be negatively affected by high peak doses of muscle relaxants, which cross-react with the lithium sensor. This can be tackled if the lithium calibration is performed before or 30 minutes after the administration of a muscle relaxant. The $\mathrm{LiDCO}^{\mathrm{TM}}$ plus system, in combination with a hemodynamic treatment protocol (targeting an oxygen delivery $>600 \mathrm{ml} / \mathrm{min} / \mathrm{m}^{2}$, was shown to be associated with reduced complications and length of hospital stay in patients after major general surgery [14]. The primary indication for the uncalibrated $\mathrm{LiDCO}^{\mathrm{TM}}$ rapid is its perioperative use for SV optimization. Therefore, the LiDCOrapid trend analysis is more important than absolute cardiac output values (which may differ when compared with cardiac output assessed by PAC).

FloTrac $^{\mathrm{TM}} /$ Vigileo $^{\mathrm{TM}}$ system: The FloTrac ${ }^{\mathrm{TM}} / \mathrm{Vigileo}^{\mathrm{TM}}$ system (Edwards LifeSciences, Irvine, USA) requires a proprietary transducer, the FloTrac ${ }^{\mathrm{TM}}$, which is attached to a standard non-proprietary radial or femoral arterial catheter and is connected to the Vigileo ${ }^{\mathrm{TM}}$ monitor. The FloTrac ${ }^{\mathrm{TM}} / \mathrm{Vigileo}^{\mathrm{TM}}$ system does not require calibration. To estimate cardiac output, the standard deviation of pulse pressure sampled during a time window of 20 seconds is correlated with 'normal' SV based on the patient's demographic data (age, sex, height, and weight) and a built-in database containing information about cardiac output assessed by the PAC in a variety of clinical scenarios. Impedance is also derived from these data, whereas vascular compliance and resistance are determined using arterial waveform analysis. After conflicting results of early validation studies, the cardiac output algorithm has been repeatedly modified in the last 5 years. This has resulted in an improved performance primarily in perioperative setting $[15,16]$. Further software modifications addressed the issue of limited accuracy during hyperdynamic situations and preliminary data showed improved cardiac output measurements under these specific conditions. However, accuracy of the device during rapid hemodynamic changes remains a major concern [17]. Nevertheless, a study using the Flotrac $^{\mathrm{TM}} / \mathrm{Vigileo}^{\mathrm{TM}}$ system for intraoperative hemodynamic optimization recently demonstrated a decreased complication rate and a reduced length of hospital stay [18].

A new cardiac output monitoring device based on pulse pressure analysis, which is calibrated by transpulmonary thermodilution - the EV $1000^{\mathrm{TM}} / \mathrm{VolumeView}^{\mathrm{TM}}$ system from Edwards Lifesciences - is currently being tested and will soon be released for its use in daily practice.

Pressure recording analytical method (PRAM): Another method to estimate SV continuously without calibration is the PRAM - MostCare ${ }^{\circ}$ (Vytech, Padova, Italy), which is based on mathematical assessment of the pressure signal obtained from an arterial line without calibration. 
PRAM has been validated so far in a porcine model under various hemodynamic states [19] and in humans undergoing cardiac surgery [20]. Similar to other devices that use pulse contour analysis, the accuracy of PRAMderived cardiac output is affected by the quality of the pressure signal and by factors that interfere with the ability to detect a pressure signal.

Nexfin $^{\mathrm{TM}}$ : The Nexfin ${ }^{\mathrm{TM}}$ HD (BMEYE B.V, Amsterdam, Netherlands) is a completely non-invasive pulse pressure analysis device that assesses pulse pressure using photoelectric plethysmography in combination with a volume-clamp technique (inflatable finger cuff). Cardiac output is derived using the so-called Modelflow method (simulation of a three-element Windkessel model). Regarding validation of the device, only limited published data are available [21].

\section{Doppler cardiac output monitoring devices}

Cardiac output can be estimated non-invasively using esophageal or transthoracic Doppler probes. Esophageal Doppler devices measure blood flow in the descending aorta and estimate cardiac output by multiplying the cross sectional area of the aorta by blood flow velocity. The aortic diameter is obtained from a built-in nomogram or by direct measurement using M-mode echocardiography. Several esophageal Doppler probes are available commercially: ODM II ${ }^{\mathrm{TM}}$ (Abbott, Maidenhead, UK), CardioQ ${ }^{\mathrm{TM}}$ (Deltex Medical Ltd, Chichester, Sussex, UK), and HemoSonic100 ${ }^{\mathrm{TM}}$ (Arrow, Reading, PA, USA). The latter device is a combination of a Doppler and an Mmode probe, the production of which has been stopped recently. There are several limitations for the use of esophageal Doppler devices. First, the device measures blood flow in the descending aorta and makes an assumption of a fixed partition between flow to the cephalic vessels and to the descending aorta. Although this may be valid in healthy volunteers, this relationship may change in patients with co-morbidities and under conditions of hemodynamic instability. Second, Doppler probes are smaller than conventional transesophageal echocardiography probes and position may change unintentionally, thus limiting continuous cardiac output assessment. Since probe position is crucial to obtaining an accurate measurement of aortic blood flow, this device is operator-dependent and studies have shown that 1012 insertions are required to obtain accurate measurements [22] with an intra- and inter-observer variability of $8-12 \%$ [23]. Moreover, aortic cross-sectional area is not constant but rather dynamic in any individual patient. Thus, the use of a nomogram may result in less accurate cardiac output estimation. Despite some limitations of esophageal Doppler devices, their utility appears to be confirmed by several perioperative hemodynamic optimization studies that have consistently demonstrated a reduction in complication rates and hospital length of stay [24].

Alternatively to the esophageal route, the transthoracic approach may be used to assess cardiac output, albeit intermittently. The USCOM ${ }^{\mathrm{TM}}$ device (USCOM, Sidney, Australia) targets the pulmonary and aortic valves accessed via the parasternal and suprasternal windows in order to assess cardiac output completely non-invasively. Validation studies have revealed conflicting results, which could be explained primarily by the inherent problem of variable signal detection $[25,26]$.

\section{Applied Fick principle}

Partial $\mathrm{CO}_{2}$ rebreathing: The $\mathrm{NICO}^{\mathrm{TM}}$ system (Novametrix Medical Systems, Wallingford, USA) applies Fick principle to carbon dioxide $\left(\mathrm{CO}_{2}\right)$ in order to obtain cardiac output measurement in intubated, sedated, and mechanically ventilated patients using a proprietary disposable re-breathing loop that is attached to the ventilator circuit. The $\mathrm{NICO}^{\mathrm{TM}}$ system consists of a mainstream infrared sensor to measure $\mathrm{CO}_{2}$, a disposable airflow sensor, and a pulse oximeter. $\mathrm{CO}_{2}$ production is calculated as the product of $\mathrm{CO}_{2}$ concentration and airflow during a breathing cycle, whereas arterial $\mathrm{CO}_{2}$ content is derived from end-tidal $\mathrm{CO}_{2}$ and its corresponding dissociation curve. Every three minutes, a partial re-breathing state is generated using the attached rebreathing loop, which results in an increased end-tidal $\mathrm{CO}_{2}$ and reduced $\mathrm{CO}_{2}$ elimination. Assuming that cardiac output does not change significantly between normal and re-breathing states, the difference between normal and re-breathing ratios are used to calculate cardiac output. There are several limitations to this device including the need for intubation and mechanical ventilation with fixed ventilator settings and minimal gas exchange abnormalities [27]. Variations in ventilator settings, mechanicallyassisted spontaneous breathing, the presence of increased pulmonary shunt fraction, and hemodynamic instability have been associated with decreased accuracy [28]. Thus, this technique may be applied in a precisely defined clinical setting to mechanically ventilated patients only.

Pulsed dye densitometry: The DDG- $330^{\circ}$ analyzer (Nihon Kohden, Tokyo, Japan) allows intermittent cardiac output measurement based on transpulmonary dye dilution with transcutaneous signal detection adapted from pulse oximetry (pulsed dye densitometry): The concentration of indocyanine green (ICG) is estimated in the arterial blood flow by optical absorbance measurements after its venous injection. Cardiac output is calculated from the dye dilution curve according to the StewartHamilton principle. Unfortunately a variety of factors, e.g., vasoconstriction, interstitial edema, movement or ambient light artefacts, may limit reliable intermittent cardiac output assessment [29]. 


\section{Bioimpedance and bioreactance}

Electrical bioimpedance uses electric current stimulation for identification of thoracic or body impedance variations induced by cyclic changes in blood flow caused by the heart beating. Cardiac output is continuously estimated using skin electrodes (BioZ ${ }^{\circ}$, CardioDynamics, San Diego, USA) or electrodes mounted on an endotracheal tube (ECOM ${ }^{\mathrm{TM}}$, Conmed Corp, Utica, USA) by analyzing the occurring signal variation with different mathematical models. Despite many adjustments of the mathematical algorithms, clinical validation studies continue to show conflicting results [30,31].

Recently, however, Bioreactance ${ }^{\circ}\left(\mathrm{NICOM}^{\circ}\right.$, Cheetah Medical Ltd, Maidenhead, Berkshire, UK) a modification of thoracic bioimpedance, has been introduced [32]. In contrast to bioimpedance, which is based on the analysis of transthoracic voltage amplitude changes in response to high frequency current, the Bioreactance ${ }^{\circ}$ technique analyzes the frequency spectra variations of the delivered oscillating current. This approach is supposed to result in a higher signal-to-noise ratio and thus in an improved performance of the device. In fact, initial validation studies reveal promising results $[32,33]$.

\section{Additional hemodynamic variables}

Apart from SV and cardiac output, hemodynamic monitoring devices provide various additional hemodynamic variables (Table 2); namely, static preload variables, functional hemodynamic variables, and continuous central venous oxygen saturation $\left(\mathrm{ScvO}_{2}\right)$.

\section{Static preload variables}

Various cardiac output monitoring devices require a central venous line for calibration of the system. Thus, central venous pressure (CVP) is briefly reviewed here. CVP is traditionally assessed as an estimate of cardiac preload since true preload, which is defined as enddiastolic myocardial fiber tension, cannot be measured at the bedside. Several factors, however, affect CVP readings including impaired right ventricular (RV) function, and severe pulmonary or valvular heart disease. Although the majority of physicians use CVP in order to guide fluid therapy [34], several studies have shown lack of correlation between CVP and SV [35,36]. Moreover, absolute CVP cannot be used to assess preload responsiveness. Therefore, the utility of CVP is limited and changes in trend over time and cyclic changes induced by mechanical ventilation are more important than absolute numbers. In contrast to the pressure preload variables, the so-called volumetric preload variables are considered to be superior indicators of preload. Global end-diastolic volume (GEDV) and extravascular lung water (EVLW) are static volumetric parameters that are assessed by transpulmonary thermodilution, which is required for the calibration of the PiCCOplus device and the upcoming EV1000/VolumeView device. Different studies have shown a better correlation between GEDV and SV than between the latter and static pressure preload [35]. GEDV could thus be used to better guide perioperative fluid therapy than pressure preload parameters [37]. EVLW on the other hand can be used to differentiate between cardiac versus non-cardiac pulmonary edema, and has been identified as an independent predictor of survival in critically ill patients [38]. It may, therefore, be of value in tailoring therapy in patients with acute respiratory distress syndrome (ARDS).

\section{Functional hemodynamic variables}

Pulse pressure analysis devices provide an automated quantification of SV variation (SVV) and some also allow the determination of pulse pressure variation (PPV). The basis of these functional variables is cyclic changes in intrathoracic pressure during positive pressure ventilation which induce changes in SV and pulse pressure as a result of a reduction in preload. The different functional hemodynamic variables have been shown to be able to predict fluid responsiveness in various studies [39], whereas static preload variables have not [40]. Nonetheless, it has to be emphasized that cardiovascular and ventilatory limitations, such as arrhythmias, right heart failure, spontaneous breathing activity, and low tidal volume ( $<8 \mathrm{ml} / \mathrm{kg}$ body weight) affect the reliability of these dynamic indices of fluid responsiveness. Under these circumstances, 'passive leg raising' could be employed to assess fluid responsiveness as it results in an internal fluid shift from the legs to the central compartment caused by the modified Trendelenburg position. This technique has been demonstrated to reliably determine fluid responsiveness in critically ill patients [41].

\section{Central venous oxygen saturation}

$\mathrm{ScvO}_{2}$ is used as a global marker of the balance between systemic oxygen supply and demand [42]. It can be easily measured by obtaining a blood sample drawn from a central venous catheter, compared with $\mathrm{SvO}_{2}$, which requires placement of a PAC and the withdrawal of blood from the distal port of the catheter. In addition to intermittent measurements using a blood sample and a blood gas analyzer, both $\mathrm{ScvO}_{2}$ and $\mathrm{SvO}_{2}$ can be measured continuously using proprietary central venous and pulmonary artery catheters, respectively. There are no outcome studies that compare intermittent versus continuous measurements of $\mathrm{ScvO}_{2}$ or $\mathrm{SvO}_{2}$; however, the only study that showed a survival benefit using $\mathrm{ScvO}_{2}$ as a resuscitation endpoint employed continuous measurement [43]. Using proprietary catheters, continuous measurements of $\mathrm{ScvO}_{2}$ can be obtained from both 
Table 2. Overview of hemodynamic monitoring techniques

\begin{tabular}{|c|c|c|c|c|c|c|c|}
\hline \multirow[b]{2}{*}{ Groups } & \multirow[b]{2}{*}{ Examples } & \multirow[b]{2}{*}{ Features } & \multirow[b]{2}{*}{ Invasiveness } & \multicolumn{4}{|c|}{ Additional variables } \\
\hline & & & & $\begin{array}{l}\text { Continuous } \\
\text { CO }\end{array}$ & Static & Dynamic & $\mathrm{SvO}_{2} / \mathrm{ScvO}_{2}$ \\
\hline \multicolumn{8}{|l|}{ PAC } \\
\hline & Vigilance $\mathrm{e}^{\mathrm{TM}}$ & $\begin{array}{l}\text { Right heart } \\
\text { catheterization }\end{array}$ & man & $\begin{array}{l}\text { Response } \\
\text { time up to } \\
12 \text { minutes }\end{array}$ & $\begin{array}{l}\text { CVP } \\
\text { PCWP }\end{array}$ & - & $\begin{array}{l}\text { Specific catheter } \\
\text { for continuous } \\
\text { measurement } \\
\text { available }\end{array}$ \\
\hline \multicolumn{8}{|l|}{$\begin{array}{l}\text { Pulse wave } \\
\text { analysis }\end{array}$} \\
\hline \multirow[t]{3}{*}{ Calibrated } & PiCCOplus ${ }^{\top M}$ & $\begin{array}{l}\text { Thermistor-tipped } \\
\text { arterial catheter } \\
\text { Central venous } \\
\text { line }\end{array}$ & $\mathbf{m}$ & $\begin{array}{l}\text { Response time } \\
3 \text { seconds }\end{array}$ & $\begin{array}{l}\text { CVP } \\
\text { GEDV } \\
\text { EVLW }\end{array}$ & $\begin{array}{l}\text { SWV } \\
\text { PPV }\end{array}$ & $\begin{array}{l}\text { Specific catheter } \\
\text { for continuous } \\
\text { measurement } \\
\text { available }\end{array}$ \\
\hline & LiDCOplus'M & $\begin{array}{l}\text { Lithium dilution } \\
\text { set }\end{array}$ & $\square$ & Beat-by-beat & - & $\begin{array}{l}\text { SWV } \\
\text { PPV }\end{array}$ & - \\
\hline & $\begin{array}{l}\text { EV1000 } \\
\text { VolumeView }^{\text {TM* }}\end{array}$ & $\begin{array}{l}\text { Thermistor-tipped } \\
\text { arterial catheter } \\
\text { Central venous } \\
\text { line }\end{array}$ & $\mathbf{m}$ & NA & $\begin{array}{l}\text { CVP } \\
\text { GEDV } \\
\text { EVLW }\end{array}$ & SWV & $\begin{array}{l}\text { Specific catheter } \\
\text { for continuous } \\
\text { measurement } \\
\text { available }\end{array}$ \\
\hline \multirow[t]{5}{*}{ Uncalibrated } & FloTrac/Vigileo ${ }^{\mathrm{TM}}$ & $\begin{array}{l}\text { Specific arterial } \\
\text { pressure sensor }\end{array}$ & घ & $\begin{array}{l}\text { Response time } \\
20 \text { seconds }\end{array}$ & - & SWV & $\begin{array}{l}\text { Specific catheter } \\
\text { for continuous } \\
\text { measurement } \\
\text { available }\end{array}$ \\
\hline & LiDCOrapidTM $^{\top \mathrm{M}}$ & $\begin{array}{l}\text { Regular arterial } \\
\text { line }\end{array}$ & घ & Beat-by-beat & - & $\begin{array}{l}\text { SVV } \\
\text { PPV }\end{array}$ & - \\
\hline & PulsioFlex ${ }^{\mathrm{TM} *}$ & $\begin{array}{l}\text { Regular arterial } \\
\text { line Specific } \\
\text { sensor }\end{array}$ & घ & NA & - & $\begin{array}{l}\text { SVV } \\
\text { PPV }\end{array}$ & $\begin{array}{l}\text { Specific catheter } \\
\text { for continuous } \\
\text { measurement } \\
\text { available }\end{array}$ \\
\hline & PRAM MostCare ${ }^{\circledast}$ & Specific arterial kit & घ & Beat-by-beat & - & $\begin{array}{l}\text { SVV } \\
\text { PPV }\end{array}$ & - \\
\hline & Nexfin ${ }^{T M} H D$ & $\begin{array}{l}\text { Specific pressure } \\
\text { sensors }\end{array}$ & $\square$ & Beat-by-beat & - & - & - \\
\hline \multicolumn{8}{|l|}{ Doppler } \\
\hline TE & CardioQ $^{\mathrm{TM}}$ & $\begin{array}{l}\text { Esophageal } \\
\text { Flowprobe }\end{array}$ & घ & $\begin{array}{l}\text { Limitation: } \\
\text { probe } \\
\text { positioning }\end{array}$ & - & - & - \\
\hline $\mathrm{TT}$ & USCOM ${ }^{\top M}$ & Flowprobe & $\square$ & Intermittent & - & - & - \\
\hline \multicolumn{8}{|l|}{$\begin{array}{l}\text { Applied Fick } \\
\text { principle }\end{array}$} \\
\hline $\begin{array}{l}\text { Partial } \mathrm{CO}_{2} \\
\text { rebreathing }\end{array}$ & $\mathrm{NiCO}{ }^{\mathrm{MM}}$ & Rebreating loop & घ & $\begin{array}{l}\text { Up-date } \\
\text { every } 3^{\prime}\end{array}$ & - & - & - \\
\hline Dye dilution & DDG analyzer ${ }^{\oplus}$ & Specific sensor & घ & Intermittent & - & - & - \\
\hline \multicolumn{8}{|l|}{$\begin{array}{l}\text { Bioimpedance/ } \\
\text { Bioreactance }\end{array}$} \\
\hline $\begin{array}{l}\text { Endotracheal } \\
\text { bioimpedance }\end{array}$ & $\mathrm{ECOM}^{\mathrm{TM}}$ & $\begin{array}{l}\text { Specific } \\
\text { endotracheal } \\
\text { tube, arterial line }\end{array}$ & - & Continuous & - & - & - \\
\hline $\begin{array}{l}\text { Thoracic/ } \\
\text { whole body } \\
\text { bioimpedance }\end{array}$ & $\mathrm{Bio}^{\circledast}$ & $\begin{array}{l}\text { Specific } \\
\text { electrodes }\end{array}$ & $\square$ & Continuous & - & - & - \\
\hline $\begin{array}{l}\text { Thoracic } \\
\text { bioreactance }\end{array}$ & $\mathrm{NICOM}{ }^{\top M}$ & $\begin{array}{l}\text { Specific } \\
\text { electrodes }\end{array}$ & $\square$ & Continuous & - & SWV & - \\
\hline
\end{tabular}

CO: cardiac output; CVP: central venous pressure; EVLW: extravascular lung water; GEDV: global end-diastolic volume; NA: technical specifications not yet available; PAC: pulmonary artery catheter; PAOP: pulmonary artery occlusion pressure; PPV: pulse pressure variation; $\mathrm{SvO}_{2}$ : mixed venous oxygen saturation; $\mathrm{ScvO}_{2}$; central venous oxy gen saturation; SVV; stroke volume variation; TE: transesophageal; TT: transthoracic; ${ }^{*}$ not yet available. 


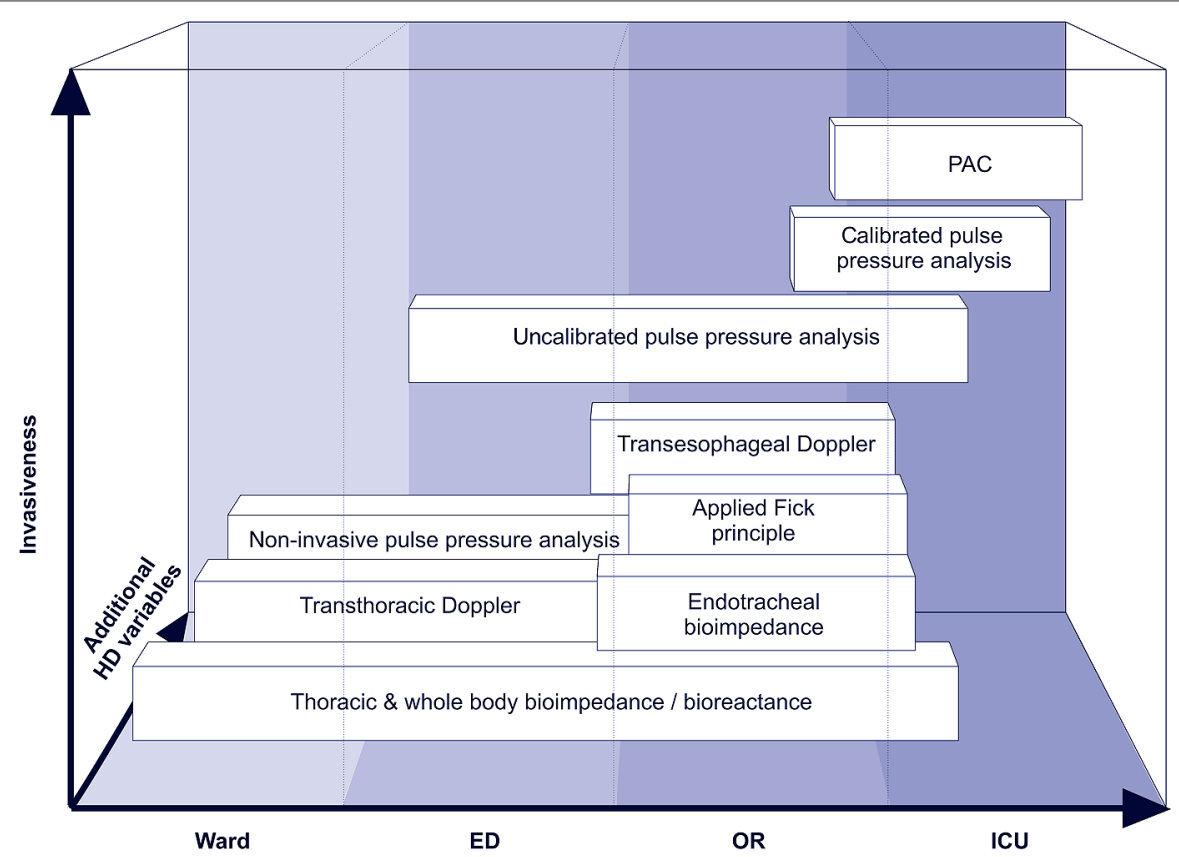

Figure 2. Integrative concept for the use of cardiac output monitoring devices. ED: emergency department; HD: hemodynamic; ICU: intensive care unit; OR: operating room; PAC: pulmonary artery catheter.

the Vigileo ${ }^{\mathrm{TM}}$ and the $\mathrm{PiCCO}^{\mathrm{TM}}$ systems. As far as its clinical utility is concerned, $\mathrm{ScvO}_{2}$ has been used as a resuscitation endpoint in patients with severe sepsis and septic shock [43]. It is important to realize that absolute $\mathrm{ScvO}_{2}$ and $\mathrm{SvO}_{2}$ values may differ considerably in different clinical situations; however, a strong correlation of their trends over time has been demonstrated [44].

\section{Integrative concept}

Considering the technical features and the typical limitations of the different cardiac output monitoring techniques it is obvious that no single device can comply with all clinical requirements. Therefore, different devices may be used in an integrative concept along a typical clinical patient pathway (Fig. 2) based on the invasiveness of the devices and the available additional hemodynamic variables (Table 2). Bioreactance may be used on the ward or in the emergency department to assess cardiac output initially in order to confirm a preliminary diagnosis. Its use may be expanded in the perioperative and ICU setting. Partial $\mathrm{CO}_{2}$-rebreathing requires an intubated and mechanically ventilated patient for cardiac output estimation. Thus, this technique may be primarily used during an operation. Uncalibrated pulse pressure analysis devices may be the primary choice in a perioperative setting as they provide functional hemodynamic variables and thus allow comprehensive hemodynamic management. In contrast, calibrated systems may be required when postoperative complications or hemodynamicinstability occur and increased device accuracy or volumetric variables are needed for improved patient management. In the presence of factors that affect the accuracy of all minimally invasive cardiac output monitoring devices, or when pulmonary artery pressure monitoring or right heart failure treatment is required, PAC insertion may be required for patient specific therapy.

\section{Conclusion}

Various devices that allow continuous cardiac output measurement in the critically ill patient are commercially available today. Their presence does not completely preclude but does increasingly limit the use of the PAC. A variety of factors (institutional, device related, and patient specific) influence the selection of a cardiac output monitoring device and clinicians need to understand the underlying principles and the inherent limitations of these devices. A selection of these techniques may be used in an integrative approach along a patient pathway. In combination with $\mathrm{ScvO}_{2}$ measurements, the assessment of volumetric preload variables and the functional hemodynamic variables that they provide may obviate the need for a PAC in the treatment of critically ill patients.

\section{Competing interests}

JAA has received research grants from Edwards Lifesciences, Irvine, CA, USA. $M C$ has received lecturing fees and research funding from Cheetha Medical Ltd, Maidenhead, UK, Edwards Lifesceinces, Irvine, CA, USA and LiDCO Ltd, 
Cambridge, UK. CKH has received lecturing fees and research grants from Edwards Lifesciences, Irvine, CA, USA, Pulsion Medical Systems, Munich, Germany and CSL Behring, Berne Switzerland.

\section{List of abbreviations used}

CVP: central venous pressure; EVLW: extravascular lung water; GEDV: global end-diastolic volume; ICG: indocyanine green; PAC: pulmonary artery catheter; PPV: pulse pressure variation; $\mathrm{RV}$ : right ventricular; $\mathrm{ScvO}_{2}$ : central venous oxygen saturation; $\mathrm{SV}$ : stroke volume; $\mathrm{SVO}_{2}$ : mixed venous oxygen saturation; SVV: SV variation.

\section{Author details}

'Department of Anesthesia and Critical Care, King Abdulaziz University, PO Box 31648, 21418 Jeddah, Saudi Arabia. ${ }^{2}$ Department of General Intensive Care, St George's Hospital and Medical School, Blackshaw Road, SW17 0QT, London, UK. ${ }^{3}$ Institute of Anesthesiology and Intensive Care Medicine, Triemli City Hospital, Birmensdorfersr. 497, 8063 Zurich, Switzerland.

Published: 22 March 2011

\section{References}

1. Connors AF Jr, Speroff T, Dawson NV, et al.: The effectiveness of right heart catheterization in the initial care of critically ill patients. SUPPORT Investigators. JAMA 1996, 276:889-897.

2. Harvey S, Stevens K, Harrison D, et al: An evaluation of the clinical and costeffectiveness of pulmonary artery catheters in patient management in intensive care: a systematic review and a randomised controlled trial. Health Technol Assess 2006, 10:1-133.

3. Lees N, Hamilton M, Rhodes A: Clinical review: Goal-directed therapy in high risk surgical patients. Crit Care 2009, 13:231

4. Funk D, Sebat F, Kumar A: A systems approach to the early recognition and rapid administration of best practice therapy in sepsis and septic shock. Curr Opin Crit Care 2009, 15:301-307.

5. Harvey S, Harrison DA, Singer M, et al:: Assessment of the clinical effectiveness of pulmonary artery catheters in management of patients in intensive care (PAC-Man): a randomised controlled trial. Lancet 2005, 366:472-477.

6. Nishikawa T, Dohi S: Errors in the measurement of cardiac output by thermodilution. Can J Anaesth 1993, 40:142-153.

7. Aranda M, Mihm FG, Garrett S, Mihm MN, Pearl RG: Continuous cardiac output catheters: delay in in vitro response time after controlled flow changes. Anesthesiology 1998, 89:1592-1595.

8. Leather HA, Vuylsteke A, Bert C, et al: Evaluation of a new continuous cardiac output monitor in off-pump coronary artery surgery. Anaesthesia 2004, 59:385-389.

9. Hamzaoui $\mathrm{O}$, Monnet $\mathrm{X}$, Richard $\mathrm{C}$, et al.: Effects of changes in vascular tone on the agreement between pulse contour and transpulmonary thermodilution cardiac output measurements within an up to 6-hour calibration-free period. Crit Care Med 2008, 36:434-440

10. Button D, Weibel L, Reuthebuch O, et al:: Clinical evaluation of the FloTrac/ Vigileo system and two established continuous cardiac output monitoring devices in patients undergoing cardiac surgery. Br J Anaesth 2007, 99:329-336.

11. Della Rocca G, Costa MG, Coccia C, et al:: Cardiac output monitoring: aortic transpulmonary thermodilution and pulse contour analysis agree with standard thermodilution methods in patients undergoing lung transplantation. Can J Anaesth 2003, 50:707-711.

12. Cecconi M, Fawcett J, Grounds RM, Rhodes A: A prospective study to evaluate the accuracy of pulse power analysis to monitor cardiac output in critically ill patients. BMC Anesthesiol 2008, 8:3.

13. Cecconi M, Dawson D, Grounds RM, Rhodes A: Lithium dilution cardiac output measurement in the critically ill patient: determination of precision of the technique. Intensive Care Med 2009, 35:498-504

14. Pearse R, Dawson D, Fawcett J, Rhodes A, Grounds RM, Bennett ED: Early goal-directed therapy after major surgery reduces complications and duration of hospital stay. A randomised, controlled trial [ISRCTN38797445]. Crit Care 2005, 9:R687-R693.

15. Mayer J, Boldt J, Poland R, Peterson A, Manecke GR Jr: Continuous arteria pressure waveform-based cardiac output using the FloTrac/Vigileo: a review and meta-analysis. J Cardiothorac Vasc Anesth 2009, 23:401-406.

16. Senn A, Button D, Zollinger A, Hofer CK: Assessment of cardiac output changes using a modified FloTrac/Vigileo algorithm in cardiac surgery patients. Crit Care 2009, 13:R32.

17. Camporota L, Beale R: Pitfalls in haemodynamic monitoring based on the arterial pressure waveform. Crit Care 2010, 14:124.

18. Mayer J, Boldt J, Mengistu AM, Rohm KD, Suttner S: Goal-directed intraoperative therapy based on autocalibrated arterial pressure waveform analysis reduces hospital stay in high-risk surgical patients: a randomized, controlled trial. Crit Care 2010, 14:R18.

19. Scolletta S, Romano SM, Biagioli B, Capannini G, Giomarelli P: Pressure recording analytical method (PRAM) for measurement of cardiac output during various haemodynamic states. Br J Anaesth 2005, 95:159-165.

20. Giomarelli P, Biagioli B, Scolletta S: Cardiac output monitoring by pressure recording analytical method in cardiac surgery. Eur J Cardiothorac Surg 2004, 26:515-520.

21. Stover JF, Stocker R, Lenherr R, et al: Noninvasive cardiac output and blood pressure monitoring cannot replace an invasive monitoring system in critically ill patients. BMC Anesthesiol 2009, 9:6.

22. Lefrant $J Y$, Bruelle $P, A y a A G$, et al:: Training is required to improve the reliability of esophageal Doppler to measure cardiac output in critically il patients. Intensive Care Med 1998, 24:347-352.

23. Valtier B, Cholley BP, Belot JP, et al:: Noninvasive monitoring of cardiac output in critically ill patients using transesophageal Doppler. Am J Respir Crit Care Med 1998, 158:77-83.

24. Abbas SM, Hill AG: Systematic review of the literature for the use of oesophageal Doppler monitor for fluid replacement in major abdominal surgery. Anaesthesia 2008, 63:44-51.

25. Chan JS, Segara D, Nair P: Measurement of cardiac output with a noninvasive continuous wave Doppler device versus the pulmonary artery catheter: a comparative study. Crit Care Resusc 2006, 8:309-314.

26. Thom O, Taylor DM, Wolfe RE, et al:: Comparison of a supra-sternal cardiac output monitor (USCOM) with the pulmonary artery catheter. Br J Anaesth 2009, 103:800-804

27. Gueret G, Kiss G, Rossignol B, et al: Cardiac output measurements in offpump coronary surgery: comparison between NICO and the Swan-Ganz catheter. Eur J Anaesthesio/ 2006, 23:848-854

28. Tachibana K, Imanaka H, Takeuchi M, Takauchi Y, Miyano H, Nishimura M: Noninvasive cardiac output measurement using partial carbon dioxide rebreathing is less accurate at settings of reduced minute ventilation and when spontaneous breathing is present. Anesthesiology 2003, 98:830-837.

29. Hofer CK, Buhlmann S, Klaghofer R, Genoni M, Zollinger A: Pulsed dye densitometry with two different sensor types for cardiac output measurement after cardiac surgery: a comparison with the thermodilution technique. Acta Anaesthesiol Scand 2004, 48:653-657.

30. Ball TR, Culp BC, Patel V, et al: Comparison of the endotracheal cardiac output monitor to thermodilution in cardiac surgery patients. J Cardiothorac Vasc 2010, 24:762-766.

31. Gujjar AR, Muralidhar K, Banakal S, et al: Non-invasive cardiac output by transthoracic electrical bioimpedence in post-cardiac surgery patients: comparison with thermodilution method. J Clin Monit Comput 2008 22:175-180

32. Squara P, Denjean D, Estagnasie P, Brusset A, Dib JC, Dubois C: Noninvasive cardiac output monitoring (NICOM): a clinical validation. Intensive Care Med 2007. 33:1191-1194.

33. Raval NY, Squara P, Cleman M, Yalamanchili K, Winklmaier M, Burkhoff D: Multicenter evaluation of noninvasive cardiac output measurement by bioreactance technique. J Clin Monit Comput 2008, 22:113-119.

34. Boldt J, Lenz M, Kumle B, Papsdorf M: Volume replacement strategies on intensive care units: results from a postal survey. Intensive Care Med 1998 24:147-151

35. Hofer CK, Furrer L, Matter-Ensner S, et al: Volumetric preload measurement by thermodilution: a comparison with transoesophageal echocardiography. Br J Anaesth 2005, 94:748-755.

36. Kumar A, Anel R, Bunnell E, et al:: Pulmonary artery occlusion pressure and central venous pressure fail to predict ventricular filling volume, cardiac performance, or the response to volume infusion in normal subjects. Crit Care Med 2004, 32:691-699.

37. Goepfert MS, Reuter DA, Akyol D, et al: Goal-directed fluid management reduces vasopressor and catecholamine use in cardiac surgery patients. Intensive Care Med 2007, 33:96-103.

38. Sakka SG, Klein M, Reinhart K, Meier-Hellmann A: Prognostic value of extravascular lung water in critically ill patients. Chest 2002, 
122:2080-2086

39. Marik PE, Cavallazzi R, Vasu T, Hirani A: Dynamic changes in arterial waveform derived variables and fluid responsiveness in mechanically ventilated patients: a systematic review of the literature. Crit Care Med 2009, 37:2642-2647.

40. Marik PE, Baram M, Vahid B: Does central venous pressure predict fluid responsiveness? A systematic review of the literature and the tale of seven mares. Chest 2008, 134:172-178.

41. Monnet X, Teboul JL: Passive leg raising. Intensive Care Med 2008 34:659-663

42. Marx G, Reinhart K: Venous oximetry. Curr Opin Crit Care 2006, 12:263-268.

43. Rivers E, Nguyen B, Havstad S, et al:: Early goal-directed therapy in the treatment of severe sepsis and septic shock. N Engl J Med 2001, 345:1368-1377.

44. Dueck MH, Klimek M, Appenrodt S, Weigand C, Boerner U: Trends but not individual values of central venous oxygen saturation agree with mixed venous oxygen saturation during varying hemodynamic conditions. Anesthesiology 2005, 103:249-257.

doi:10.1186/cc9996

Cite this article as: Alhashemi JA, et al: Cardiac output monitoring: an integrative perspective. Critical Care 2011, 15:214. 